\title{
Personal Communication
}

National Cancer Institute

\section{Source}

National Cancer Institute. Personal Communication. NCI Thesaurus. Code C17465.

The exchange of information between people. Often used as a citation when information is passed from one researcher to another, but is not published. 